\title{
Advanced Control Methods for Power Converters in DG Systems and Microgrids
}

\author{
Dragicevic, Tomislav; Vazquez, Sergio; Wheeler, Patrick
}

Published in:

IEEE Transactions on Industrial Electronics

Link to article, DOI:

10.1109/TIE.2020.2994857

Publication date:

2021

Document Version

Peer reviewed version

Link back to DTU Orbit

Citation (APA):

Dragicevic, T., Vazquez, S., \& Wheeler, P. (2021). Advanced Control Methods for Power Converters in DG Systems and Microgrids. IEEE Transactions on Industrial Electronics, 68(7), 5847 - 5862.

https://doi.org/10.1109/TIE.2020.2994857

\section{General rights}

Copyright and moral rights for the publications made accessible in the public portal are retained by the authors and/or other copyright owners and it is a condition of accessing publications that users recognise and abide by the legal requirements associated with these rights.

- Users may download and print one copy of any publication from the public portal for the purpose of private study or research.

- You may not further distribute the material or use it for any profit-making activity or commercial gain

- You may freely distribute the URL identifying the publication in the public portal

If you believe that this document breaches copyright please contact us providing details, and we will remove access to the work immediately and investigate your claim. 


\title{
Advanced Control Methods for Power Converters in DG Systems and Microgrids
}

\author{
Tomislav Dragičević, Senior Member, IEEE, Sergio Vazquez, Senior Member, IEEE, \\ and Pat Wheeler, Senior Member, IEEE
}

\begin{abstract}
In recent years, different advanced control methods have been successfully proposed as alternatives to conventional cascaded linear controllers for power converters in distributed generation systems and microgrids. The prime movers of this research are strong capabilities of advanced controllers to improve the dynamic performance and robustness of power electronic converters in these applications. This paper first introduces the key roles and functionalities of voltage source converters (VSCs) in distributed generation systems and microgrids. Then, it describes how these functionalities are traditionally achieved by using linear controllers, and addresses their fundamental dynamic performance limitations. Afterwards, the most prominent advanced control methods are overviewed. In this context, the implementation principles, advantages and disadvantages of prominent model- and data-based advanced control methods are critically discussed and experimentally compared. The paper ends with a discussion about promising research directions in the area of advanced control for power electronic converters.
\end{abstract}

Index Terms-Advanced control, distributed generation, voltage source converters (VSCs).

\section{INTRODUCTION}

$\mathbf{T}$ RADITIONAL approach for controlling voltage source converters (VSCs) in distributed generation (DG) systems and microgrids is the so-called voltage-oriented control (VOC) [1]. VOC is based on a cascaded control structure followed by a pulse-width-modulator (PWM). Here, the control loops regulate converter state variables by computing an output voltage reference, which is then synthesized by the PWM stage. VOC principle is well understood and it can be precisely analyzed, because it consists of linear control loops. This allows simple and analytical control synthesis, as well as clear performance quantification of the control strategy [2]-[4].

In spite of its advantages, VOC entails several practical limitations. For instance, due to its linear nature, tuning of control parameters is valid only for a certain operating point. This means that the response characteristics of the VSC cannot be guaranteed during large-signal external disturbances. For

Manuscript received Month December 5th, 2019; revised Month April 6th, 2020; accepted Month May 1st, 2020. ).

Tomislav Dragičević is with the Center of Electric Power and Energy, Technical University of Denmark, 2800 Kgs. Lyngby, Denmark (e-mail tomdr@elektro.dtu.dk).

Sergio Vazquez is with the Electronics Department, Universidad de Sevilla Sevilla, C.P. 41092 Spain (e-mail: sergi@us.es). Sergio Vazquez gratefully acknowledges the financial support provided by the Spanish Science and Innovation Ministry under project TEC2016- 78430-R

Pat Wheeler is with the Department of Electrical and Electronics Engineering, University of Nottingham, Nottingham NG7 2RD, U.K. (e-mail Pat.Wheeler@nottingham.ac.uk) instance, such disturbances can be caused by high-power pulsating loads because they result in significantly altered current. They can also be caused by faults in the grid because they result in significantly altered voltage at the point of common coupling. Another issue is that due to design of controllers for specific parameters and operating point, parameter variations may compromise the stability of the system if not properly accounted for. While robustness can be embedded in the linear control system design, it is challenging to ensure the performance when both parameter variations and large-signal disturbances occur simultaneously. Finally, cascaded control has inherently limited dynamic response. This is because every outer loop needs to be designed with approximately an order of magnitude smaller bandwidth compared to the inner one, in order to avoid interference between them [5].

Significant research efforts in control of VSCs have been carried out over the past several years to avoid some of the disadvantages of cascaded linear control structures. One major branch of that research was dedicated to improve the performance of VSCs by introducing innovative feedback loops, but maintaining the cascaded control organization and a high share of linear controllers [2]-[4]. However, although these modifications may bring some improvements, they do not remove the fundamental limitations of cascaded linear control schemes. Namely, no matter what innovative feedback loop is introduced, the control structure backbone still remains dependent on linear cascaded control structure. This means that both small and large-signal performance of the system will be in any case inevitably limited.

Another approach, referred to as Advanced Control, is concerned about conceptually different control methods, particularly in the way how they process the error between the measured signals and references. Advanced control methods can be divided into model-based and data-based strategies. In the first category, models of the converter and its corresponding filter are explicitly used in the controller design process. In the data-based category, controllers are designed without explicitly considering the model but by using the qualitative knowledge about the VSC and data extracted from the VSC simulation model or experimental test-bed. Some of the most notable model-based advanced control strategies are state feedback control (SFC) [6]-[8], sliding-mode control (SMC) [9]-[12], and model-predictive control (MPC) [13][17]. On the other hand, prominent data-based controllers rely on structures such as fuzzy-interference systems [18]-[22] and artificial neural networks (ANNs) [23]-[26] to process various signals in the VSC control system. 
It is important to highlight that control systems for VSCs for DG systems and microgrids can in principle be divided into inner (responsible for local voltage and current control) and outer control loops (responsible for power sharing control). Advanced control methods have thus far mainly been applied to the inner loops. For instance, they can be used as supplementary control loops, where they are deployed as simple one-to-one replacements of specific conventional controllers in the cascaded control structure. Another alternative is that they can merge several control stages into a multi-input multi-output (MIMO) control system. Both approaches have been shown to be an effective way of improving the VSC performance in numerous applications. It should be noted that excellent review articles about conventional cascaded linear inner control loops and outer loops for VSCs already exist (e.g. see [2] for overview of both inner and outer loops, and [27], [28] for overviews of outer loops). Moreover, it is important to highlight that grid connected VSCs draw power from the dc sources and convert it to ac power. In this context, architectures where multiple VSCs are connected to the same dc bus are becoming increasingly popular because the control problem is simplified [29], while at the same time the efficiency and reliability of the system is improved [30].

On the other hand, this article focuses on advanced control methods applied to inner loops for VSCs in DG systems and microgrids, targeting the control on the ac side and thus assuming that the dc link voltage is constant. Along these lines, the key aims of this article are to: 1) Reveal the limitations of linear control methods, 2) Elaborate on how can advanced controllers in principle eliminate these limitations, and 3) Make a survey about the different advanced control methods, experimentally compare them and discuss their industrial applicability.

The rest of the paper is organized as follows. The roles of VSCs in DG systems and microgrids are briefly described in Section II. Afterwards, conventional cascaded control structure for grid-tied VSCs is analyzed in Section III. Its limitations from the standpoint of achievable dynamics are studied in detail in Section IV, where the motivation for using advanced control methods is highlighted. Section V then builds on this framework by reviewing and critically comparing several prominent model- and data-based advanced control strategies, respectively. Section VI experimentally compares several advanced controllers which have been implemented on the common test setup. Section VII provides a qualitative discussion about the applicability of different control methods in practical industrial applications. Finally, the conclusions and recommendations for future research in the area of advanced VSC control are given in Section VIII.

\section{VSC ClasSifiCATION IN DG AND MiCROGRIDS}

VSCs in DG systems and microgrids can have different roles, which can be achieved by appropriate designs of their associated control systems. In principle, three main roles of VSCs can be distinguished, i.e. grid-forming, grid-feeding and grid-supporting roles. There exist several different terminologies describing these roles in the literature. Commonly used terminology defines that grid-forming inverters employ a rigid

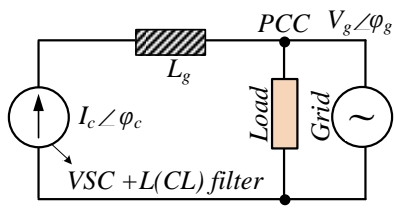

(a)

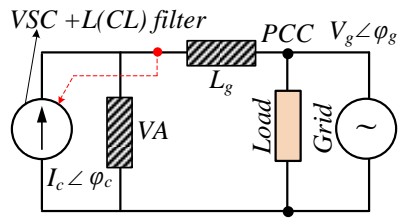

(c)

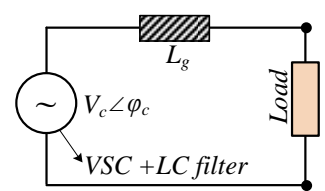

(b)

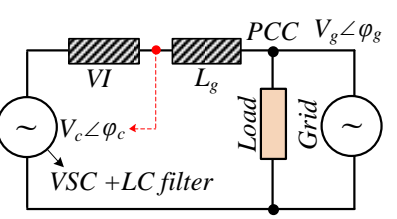

(d)
Fig. 1. Simplified representations of different VSC roles: (a) Grid-feeding VSC. (b) Grid-forming VSC. (c) Grid supporting VSC with current control. (d) Grid supporting VSC with voltage control.

voltage control, grid-feeding inverters employ rigid current or power control, while grid-supporting inverters employ flexible voltage/current/power control that is adapted online (e.g. using droop control) according to the measured (micro)grid conditions [2].

However, it is interesting to notice that some recent references (e.g. see [31]) define the term grid-forming inverters for representing both rigid voltage control and flexible voltage/current/power control. In this paper, a conventional classification was followed [2]. Under this setting, grid-forming units do not need synchronization since they define the grid, whereas all types of grid-feeding and grid-supporting VSCs can use a dedicated synchronization, like in [32]-[34] or can be operated without it, as in [35]-[37].

\section{A. Grid-feeding VSC}

Grid-feeding VSCs can either be connected to the grid through an $L$ or $L C L$ filter. Their function is to inject specified amount of current or power into the grid at the point of common coupling (PCC). The objective is to track the imposed current or power references regardless of the variations in the grid voltage and frequency. Therefore, gridfeeding VSC can be represented as a constant current source, as shown in Fig. 1(a). From the implementation point of view, it typically comprises outer control loops, which include the dc-link voltage regulator, active and reactive power controllers, and a dedicated synchronization unit. The inner loop comprises a current controller with embedded active or passive damping [38].

\section{B. Grid-forming VSC}

The function of a grid-forming VSC is to establish the local microgrid voltage. Therefore, it can be represented as an ideal voltage source, as shown in Fig. 1(b). Only one of this type of unit can operate in the system since it provides a stiff voltage control. Therefore, this unit is considered as the master in the system that defines the local microgrid. Due to this reason, grid-forming VSC does not need to have any power sharing capabilities nor dedicated synchronization. From the implementation standpoint, grid-forming VSCs are typically realized via outer voltage loop and an inner current loop [39]. As already mentioned, some references (e.g. see [31]) consider different functionalities for the grid-forming 
VSC. In the classification used in this, such functionalities are assumed to belong to the grid-supporting role and they described in the following subsection.

\section{Grid-supporting VSC}

As opposed to the first two categories, grid-supporting VSCs involve broader spectrum of control functionalities, from grid voltage/frequency support, active/reactive power sharing to black-start capability. These types of units are used to provide grid support functions and to establish microgrids through shared effort of multiple converters. Since the realization of these functionalities depends on grid feedback measurements, they are indicated by red dashed arrows in Fig. 1(c) and 1(d). Grid-supporting VSCs can be realized either as current sources, as shown in Fig. 1(c), or as voltage sources, as shown in Fig. 1(d). The former category is normally supplemented by the virtual admittance (VA) control loop, whereas the latter one with the virtual impedance (VI) loop.

Moreover, the latter category can further be split to units with direct VSC voltage control and units with filter voltage control. Advantages and disadvantages of each of these implementations are discussed next.

1) Grid-supporting VSC with current control: These units share the same physical and inner current control structure as grid-feeding VSCs. However, they have additional outer controllers, which give rise to more functionalities. In particular, grid-supporting VSCs with current control actively adapt the current reference according to grid voltage conditions in order to provide active and/or reactive power support to electrical power grid or a microgrid. Usually, the outer grid-supporting controller calculates the converter side inductor filter current reference that is sent to the inner current controller to ensure tracking [34], [40]. Another method is based on using directly the grid side current to perform the control [37]. Since the current reference is adaptive, a red dashed feedback signal is shown in Fig. 1(c). The purpose of providing active and/or reactive power support could be to provide static frequency and voltage amplitude compensation, virtual inertia emulation or others. To achieve accurate power injections, virtual admittance (VA) control loop can also be implemented to set the total admittance "seen" by the VSC [37]. Therefore, connection of VA is also indicated in 1(c).

2) Grid-supporting VSC with voltage control: A disadvantage of grid-supporting VSCs with current control is that they are not suitable for standalone mode since there is no explicit control over the bus voltage. On the other hand, grid-supporting VSCs with voltage control are suitable for standalone mode. In this case, the VSC is connected to the grid through an $L C$ filter. However, from the practical point of view, it forms an $L C L$ filter together with the grid impedance $\left(L_{g}\right)$. This category can further be split to units with direct VSC voltage control and units with output capacitor filter voltage control. In both cases, virtual impedance loop is commonly deployed for fixing the output impedance seen by the VSC [41].

a) Grid-supporting units with direct VSC voltage control: The outer grid-supporting controller calculates the voltage

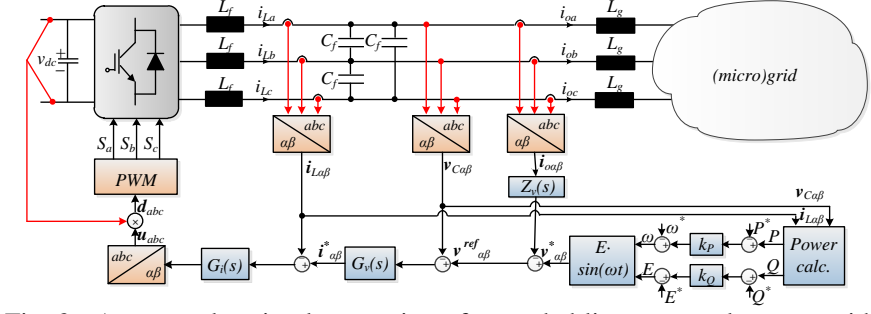

Fig. 2. An exemplary implementation of cascaded linear control system with outer control loops [2].

reference that should be generated by the VSC [32], [35], [36]. Practical concern with this implementation is that there are no inner control loops. For this reason, the converter current limitation functionality is not possible and any overcurrent condition may lead the protection circuit to trip the VSC. Moreover, as it is not possible to embed active damping of $L C L$ filter resonance without inner loops, sacrifice of VSC efficiency through passive damping is the only resort for achieving stable performance.

b) Grid-supporting units with output capacitor filter voltage control: The outer grid-supporting controller calculates the capacitor filter voltage reference that is sent to the inner voltage controller to ensure tracking [33], [42]-[44]. This is more practical implementation compared to the previous case since it enables direct control over converter current and allows straightforward embedding of active damping.

\section{Conventional Cascaded Control System}

In general, each control loop that is positioned higher in hierarchy needs to be executed at approximately an order of magnitude lower bandwidth than the one beneath to avoid dynamic interactions. An exemplary implementation of such linear cascaded control system is depicted in Fig. 2, which shows several loops, as also described below.

\section{A. AC Current Control}

Current control is the fundamental functionality that needs to be embedded in any practical VSC. It is conventionally realized by linear proportional-integral (PI) controllers in synchronous reference frame or proportional-resonant (PR) controllers in stationary reference frame, but these two schemes have been shown to be mathematically equivalent [45]. Depending on the structure of the output filter, current controller can regulate either a converter-side or a grid-side current. For instance, converter side current control is the only option in current controlled VSCs with $L$ filter [46], [47]. It is also used in case of grid-forming and grid-supporting VSCs with output capacitor filter voltage control [2], [39]. The converter side current control can be used for $L C L$ filter-type grid-feeding and grid-supporting VSCs as it introduces an inherent active damping mechanism [48]. Implementations where grid side current is directly controlled are also common, but dedicated active or passive damping is then required [49], [50].

A desirable property of current controller is to have good dynamic performance and robustness. It should also be able to follow the current references without phase or amplitude error over a wide frequency range [51]. The quantitative benchmarks 
for these requirements are established in relevant standards (e.g. [52]) and can be achieved by proper tuning of current controller using linear control theory.

Dynamic performance of such controller is mainly affected by the proportional gain, which should generally be tuned so as to set the crossover frequency of the system as high as possible with respect to desired phase margin [53]. On the other hand, tracking of harmonic current references at desired frequency can be done by imposing integral or resonant controllers. However, one needs to be cautious not to set proportional gain too high so that harmonic controllers fall outside the bandwidth of the system [26].

\section{B. Grid Fault Ride Through}

Grid connected power converters need to continue running on-line even in case of faulty grid conditions, which are normally characterized by voltage sags in one or several phases. This is because the power balance in the grid is usually disrupted during such conditions, and eventual termination of supply from additional VSCs would cause further imbalance. This situation may in the worst case scenario lead to cascaded failures and blackout of the whole grid. For this reason, the ability of VSC to stay connected with the grid and continue injecting power is a mandatory function, as specified in the grid codes [52].

The most common way of implementing this service is through external controller that monitors the grid voltage, detects the fault, and accordingly calculates the grid current reference to be sent to the inner current controller [47], [54]. It should also be noted that under voltage sags deeper than defined by the standards, the converter should be capable of performing a safe and seamless disconnection from the grid. This event is commonly referred to as the unscheduled transition to intentional island [52]. After clearing the fault, the converter should be able to seamlessly connect back to the grid [55]-[57].

\section{AC Voltage Control}

Explicit ac voltage control is required for grid-forming and grid-supporting units with output capacitor filter voltage control. Equivalently as in the case of ac current control, conventional ac voltage control is realized with linear PI or PR controllers [58], [59]. The general control structure and tuning principles are similar as for current controllers, but additional considerations concerning state-feedback decoupling needs to be accounted for [39].

In the grid forming-mode, voltage references are predefined and VSC is operated as a standalone system. Dedicated standards are applicable to quantify the performance of the VSC in this mode from both dynamic and steady-state standpoint [60]. On the other hand, voltage references are generated from external loops when VSC with capacitor filter voltage control is in grid-supporting mode. In this case, although the grid current is usually only indirectly controlled, it still needs to conform with relevant standards for grid current quality [52].

\section{Virtual Impedance/Admittance Loops}

Virtual impedance and admittance loops commonly refer to two types of feedback loops; the so called inner and outer virtual impedance/admittance controllers [61]. In the inner virtual impedance/admittance controller, feedback from state or disturbance variables is applied directly to the modulator. These types of feedback loops do not modify the functionality of the VSC, but merely affect its internal dynamic characteristics. Typical applications of inner virtual impedance and admittance loops are for active damping, computational and PWM delay compensations, disturbance rejection, statedecoupling purposes and others.

In the outer virtual impedance/admittance loops, feedback from state or disturbance variables are used to modify the current or voltage reference set points, $i_{r e f}$ and $v_{r e f}$, respectively. Examples of outer virtual impedance $\left(Z_{v i}\right)$, and virtual admittance $\left(Y_{v a}\right)$ implementations are as follows:

$$
v_{r e f}=v_{r e f}-Z_{v i}(s) i_{g}, \quad i_{r e f}=i_{r e f}-Y_{v a}(s) v_{g},
$$

where $v_{g}$ and $i_{g}$ represent the grid voltage and current, respectively.

Outer virtual impedance/admittance loops can modify the system-level behavior of the VSC and thereby achieve greater span of functionalities compared to inner virtual impedance/admittance loops. However, their effective range of operation is limited by dynamics of inner ac current and ac voltage controllers. Some common applications of outer virtual impedance/admittance loops are shaping the effective output impedance/admittance between the VSC and the grid in order to decouple of active and reactive power flows, share nonlinear and unbalanced loads between paralleled VSCs, limit fault current, damp sub-synchronous oscillations and others [62].

\section{E. Synchronization}

The most commonly deployed synchronization mechanism for VSCs is based on the phase-locked-loop (PLL), which is a nonlinear control structure that explicitly locks the converter's internal voltage signal to the fundamental component of the grid voltage. Grid voltage angle or frequency are then used in the VOC scheme to control current components either in the $d q$ synchronous or $\alpha \beta$ stationary reference frames, respectively. The basic PLL structure for three-phase applications is the so called synchronous reference frame PLL (SRF-PLL) [63]. Here, Clarke's and Park's transformations are used to transform the three-phase grid voltage signals first into $\alpha \beta$ reference frame and then into $d q$ synchronous reference frame. The resulting q-axis output is processed by a PI controller, which regulates its magnitude to zero. The signal coming out of the PI is estimated grid frequency, from which the grid voltage vector phase angle can be obtained using an additional integrator. Since the estimated phase angle signal is used in the previously described Park's transformation, the respective phase angle becomes locked to the q-axis grid voltage.

PLL synchronization provides excellent performance when VSC is connected to a stiff grid. However, PLL dynamics have a negative impact on the local VSC stability when it is connected to a weak grid [64]. Therefore, another synchronization principle has been developed specifically for this purpose, i.e. the so called power-synchronization control [35]. Here, angle of the VSC output voltage is regulated as a function of 


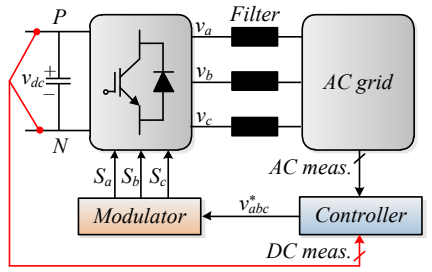

(a)

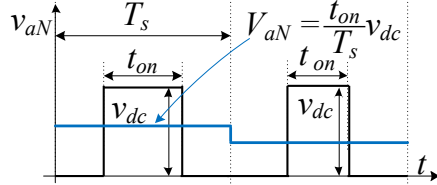

(b)
Fig. 3. Controller with modulator stage: (a) System structure. (b) VSC output voltage for phase a.

measured and reference active powers, $P$ and $P_{\text {ref }}$, respectively. Since this type of strategy does not rely on integral action, there is no explicit locking to the phase angle of the grid voltage but only its implicit control, which is equivalent to the so called power-frequency droop control, as described in the next subsection. Control strategies that combine both synchronization mechanisms have also been reported [32], [33], [36]. In these schemes, the power-synchronization has been deployed as the main synchronization method, whereas the PLL was used to extract the grid frequency that is used in the internal damping controller.

Regardless of the specific synchronization principle, distorted, faulty and unbalanced grid conditions present a challenging scenario for its design. Conventional structures can only achieve limited dynamic response under such conditions, which is problematic because of the increasingly strict grid codes. Namely, these codes define the required response of the VSC during faults, which to a large extents depends on the quick and accurate synchronization capability [65][67]. An abundance of research efforts has been dedicated to improve the performance of both PLL-based and power-based synchronization mechanisms in faulty grids. More information can be found in [68], [69] for PLL-based and in [35], [40], [70] for power-based synchronization.

\section{F. Grid Frequency and Voltage Support}

Reduced system inertia is one of the main challenges associated with high penetration of converter-based distributed generation technologies in the electrical power grid. It is manifested by ever higher frequency nadirs and faster rates-ofchange of frequency (ROCOF) [71]. To support the frequency control, modern grid codes require converters to stay connected and to continue exchanging the power with grid under moderate frequency deviations and ROCOF [52]. Moreover, VSCs must be equipped by static frequency-power droops control to continually adapt to frequency variations. The implementation of such static frequency-power droop functions can be done as an outer controller with respect to virtual impedance loop [44], [72]:

$$
\omega_{m}=-k_{p}\left(P-P_{r e f}\right)+\omega_{r e f},
$$

where $\omega_{m}$ and $\omega_{\text {ref }}$ are the virtual and nominal frequency.

Although it provides reduced frequency nadir, static frequency-power droop characteristic does not increase the inertia of the system. Therefore, grids dominated by VSCs with static frequency support characteristics exhibit high ROCOF following a load disturbance. Since this may trigger the protective relays of conventional synchronous generators

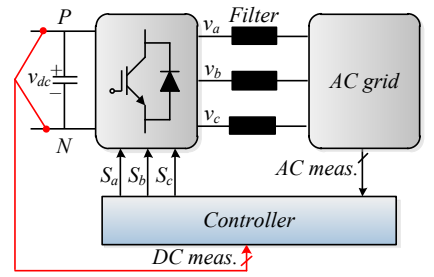

(a) (b)

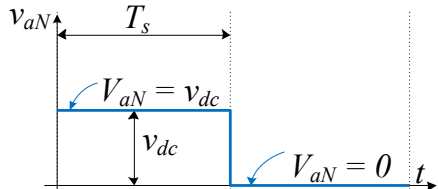

Fig. 4. Controller without modulator stage: (a) System structure. (b) VSC output voltage for phase a.

and anti-islanding protection relays, high ROCOF should be avoided. In this context, virtual inertia emulation controllers have been increasingly proposed as viable substitutes for static droop controllers [32], [33], [37]. It has been shown in [36] that both controllers have identical steady-state performance, but virtual inertia introduces additional swing-equation type dynamics that allows reduced ROCOF, as follows:

$$
P_{r e f}-k_{p}\left(\omega_{m}-\omega_{r e f}\right)-P=J \omega_{m} d \omega_{m} / d t+D\left(\omega_{m}-\omega_{g}\right),
$$

where $\omega_{g}$ is the measured frequency, while $J$ and $D$ are inertia and damping constants, respectively. If these constants are set to zero, (3) becomes equivalent to (2). Nevertheless, inertial response of power converters is still not defined as mandatory service in the latest standards [52].

Besides assisting the grid's frequency regulation, VSCs are also required to support the grid voltage by provision of reactive power services [52]. These are normally defined by imposing static reactive power vs. voltage relationship such as:

$$
V_{m}=-k_{q}\left(Q-Q_{\text {ref }}\right)+V_{\text {ref }},
$$

where $V_{m}$ and $V_{\text {ref }}$ are the measured and nominal grid voltage amplitude, respectively. $Q$ and $Q_{\text {ref }}$ are measured and reference reactive active powers, respectively, and $k_{p}$ represents the controller gain.

It can be seen that the reference values $P_{\text {ref }}, \omega_{\text {ref }}, Q_{\text {ref }}$ and $V_{\text {ref }}$ are included in (2) and (4), respectively. The purpose of these reference values is to adjust the droop curves in a way to ensure that inverter in the steady state converges to a desired operating point and this implementation is consistent with the literature [2], [27]. However, implementations where these reference values were omitted have also been reported [28]. In this case, the converter will produce zero frequency and zero voltage for zero active and zero reactive power.

\section{Limitations of CONVENTIONAL CONTROL}

This section studies the performance limitations of the conventional linear cascaded control system described above. In general, its dynamic response is mainly restricted by the control implementation principle and its hierarchical structure.

\section{A. Control Implementation Principles}

Control implementation principles are distinguished by the way in which the semiconductor switches in the VSC are being manipulated. This can be done using two main modulation approaches, as described below. 


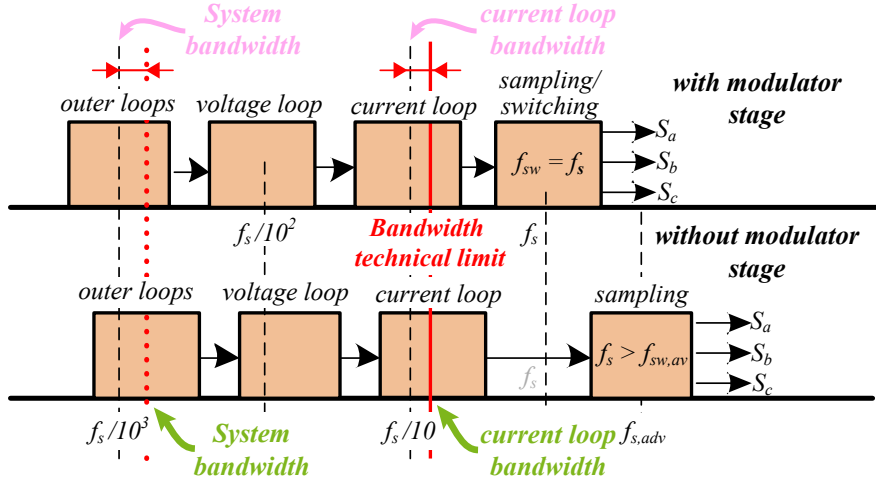

Fig. 5. Visual interpretation of time scales in cascaded VSC control system with and without modulator stage.

1) Implementation with Modulation Stage: The first implementation principle, shown in Fig. 3(a), is the one in which desired converter output voltage $v_{a b c}^{*}$ is firstly computed by the controller and then it is passed to a modulator stage. This implementation principle is also known as indirect control since the final control signals, which are the power semiconductor states, are not directly set by the control algorithm. In this case, controller can essentially be developed independently of converter topology [73]. On the other hand, objective of the modulator is to ensure that respective reference voltages are precisely synthesized at the VSC output with appropriate switching strategy.

As an example, if one leg of the simplest VSC topology (i.e. the two-level VSC) is taken, an illustrative output voltage during one sampling period is as shown in Fig. 3(b). It can be seen that the output voltage of one leg will begin and end at zero level. At some point in the sampling period, the switches are first turned on to provide voltage output of $v_{d c}$, and then turned of $f$ after $t_{o n}$. Therefore, on/off switching occurs exactly once during the $T_{s}$ period, which leads to the constant switching frequency in each leg that is equal to $f_{s w}=1 / T_{s}$. This yields predictable and concentrated harmonic voltage spectrum at the VSC's output terminals, which facilitates design of passive filters and produces low acoustic and EMI noise. Moreover, since duration of $t_{\text {on }}$ can be any number between zero and $T_{s}$, the average leg voltage, $V_{a N}=t_{o n} v_{d c} / T_{s}$ can be precisely adjusted and thus the voltage references can be tracked without steady state error.

Another important feature when the modulator stage is included, is that the switching frequency of the VSC has a locked ratio to the sampling rate [74]. Therefore, the sampling rate is limited by the permissible switching frequency of semiconductor devices. This constraint puts a limit on the bandwidth of control system because every outer loop needs to be at least an order of magnitude slower in order to avoid dynamic interactions between the neighboring loops [74].

2) Implementation without Modulation Stage: Another implementation principle, shown in Fig. 4(a), is the one where controller and modulator are combined into a single stage. As opposed to the previous case, VSC topology now needs to be considered since each topology has a different set of available switch configurations (e.g. two-level VSC, as the simplest example, has eight possible configurations). This implementation

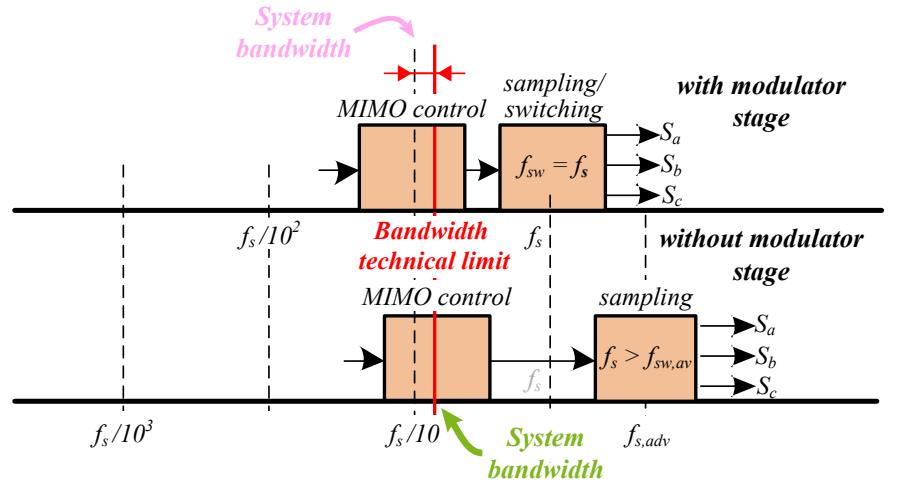

Fig. 6. Visual interpretation of time scales in MIMO control structure for VSC with and without modulator stage.

structure is also known as direct control because the outputs of the controller are the power semiconductor states at every sampling instant, which are the final control signals. For this reason, it can be categorized as a variable-structure control, which is recognized for its excellent robustness [75], [76].

Taking again as an example one leg of a two-level VSC, the output voltage during one sample period $T_{s}$ is shown in Fig. 4(b). It can be seen that the sampling instants are synchronized with the switching events. For this reason, it is only possible to have one voltage value at the VSC's output terminals during the whole sampling period, i.e. zero or $v_{d c}$. Since the output leg voltage can only take values on a discrete set, it cannot be smoothly adjusted. This situation leads to several drawbacks when compared to the implementation with modulator stage. For instance: It can present steady state errors for some control formulations and in general, it leads to higher switching ripple when both implementations use the same sampling period.

On the other hand, switching does not need to necessarily occur at every sampling instant. In general, this may be seen as a disadvantage because it leads to variable switching frequency and makes the output filter design difficult. However, it also allows sampling rate of the controller to be significantly higher than the average switching frequency. Therefore, for comparable switching frequencies, control without modulator generally leads to better dynamic characteristics than control systems that use the modulator stage [77].

\section{B. Impact of Modulation on Dynamic Performance}

This subsection qualitatively analyzes the implication of modulation principles on dynamic performance of the VSC. The upper part of Fig. 5 shows the time-scale organization of the cascaded control system including the modulator stage. Sampling $f_{s}$ and switching frequencies $f_{s w}$ are considered to be equal, i.e. $f_{s}=f_{s w}$. This means that the bandwidth of the inner controller (usually a current loop) should be set approximately an order of magnitude lower [74]. It should also be noted that depending on design of the VSC's output passive filter and the dc-link voltage value, maximum achievable bandwidth of the current loop may in theory be lower than that value. However, since this situation can generally be avoided by proper filter design methods (e.g. see [78]), a reasonable practical assumption is that system's physical constraints are 
not triggered. However, if this is not the case, the time scales represented in Fig. 5 and Fig. 6 may be shifted in accordance with different physical designs. Thus, time scales shown in Fig. 5 and Fig. 6 should be considered only as indicative ones.

The maximum bandwidth of the current control loop is in this example chosen to be slightly higher than $f_{s} / 10$ (see the solid vertical line in Fig. 5). It can be clearly seen that in general, the augmentation in the sampling rate would also increase the achievable bandwidth of the inner control loop, and this would correspondingly allow speeding up the outer loops as well. However, increasing the sampling rate has following impacts depending on the control implementation principle:

1) If the control system uses explicit modulator stage (Fig. 3 ) then, by increasing the sampling rate, switching frequency is inevitably increased as well, which may be unacceptable for deployed semiconductor devices.

2) If control and modulation are combined into a single stage (Fig. 4) then, the sampling rate can be significantly increased while average switching frequency can be kept at arbitrary level. However, increased sampling rate generally requires more powerful (and hence more expensive) control platforms.

Time scale-organization of cascaded control system without the modulator stage is illustrated in the bottom part of Fig. 5, for a sampling rate $f_{s}=f_{s, a d v}$ and an averaged switching frequency $f_{s w, a v}$. The bandwidth of current controller now can be set exactly at the technical limit while $f_{s w, a v}$ is maintained in an acceptable value for the power semiconductors. Therefore, it can be concluded that control systems which do not rely on the modulation stage have the potential of achieving better dynamic performance.

\section{Impact of Cascaded Control on Dynamic Performance}

Besides control implementation principle, dynamic performance of the system is affected by the organization of control loops. Namely, by merging two or more control loops into a MIMO control structure, the conventional cascaded organization can be avoided and dynamic performance can be improved. Assuming that modulator operates at frequency $f_{s}$, and that the maximum bandwidth is slightly higher than $f_{s} / 10$, it can be seen from time-scale diagram in the upper part of Fig. 6 that overall bandwidth of the system is significantly higher than the one with the same implementation principle in Fig. 5. The response speed of MIMO controller is constrained solely by the technical limits of the system. However, it should be noted that this limit is generally lower than the one for the inner control loop for the cascaded control structure when controlling only one variable. The reason is that MIMO controller needs to manage simultaneously variables that exhibit both fast and slow dynamics. For instance, in a VSC with an $L C$ filter, the inductor current dynamics will always be faster than the capacitor voltage dynamics.

Similarly to cascaded control loop implementation, techniques relying on MIMO control structures can be realized either with or without explicit modulator. However, it is worth noting that it is often unfeasible to combine all the control loops within one single controller. For instance, outer control loops such as dc-link voltage loop, virtual inertia emulators and others are often much slower than the inner ones. Therefore, hybrid combinations of control loops are often preferred, where only one or two inner loops are merged together while the outer ones are embedded separately on top.

\section{Advanced Control Methods}

This section discusses several advanced control methods for DG systems and microgrids, which can generally be divided into model- and data-based methods. In the following subsections, some fundamental characteristics for each one of them are first presented. Afterwards, discussion comprising relevant theoretical foundations, practical implementation details and performance characteristics for each reviewed method is given. A compact summary of this discussion is provided in Table I.

\section{A. Model-Based Advanced Control}

Model-based advanced control strategies take advantage of the model of the VSC to derive the control signal. Model is either used to make online prediction of the system states and choosing optimal actuation or for synthesizing the optimal feedback controller that acts on errors between the reference and measured signals. For digital implementation of modelbased controllers, continuous model of the plant is first discretized using the controller sampling period $T_{s}$. The generic discrete model of the plant is as follows:

$$
\begin{gathered}
\bar{x}(k+1)=A_{d} \bar{x}(k)+B_{d} \bar{u}(k) \\
\bar{y}(k)=C_{d} \bar{x}(k)+D_{d} \bar{u}(k)
\end{gathered}
$$

where $\bar{x}=\left[\bar{x}_{1}, \bar{x}_{2}, \ldots\right]$ are state variables, $\bar{y}=\left[\bar{y}_{1}, \bar{y}_{2}, \ldots\right]$ are outputs, $\bar{u}=\left[\bar{u}_{1}, \bar{u}_{2}, \ldots\right]$ are inputs and matrices $A_{d}, B_{d}, C_{d}$ and $D_{d}$ of appropriate dimension complete the model.

1) State Feedback Control (SFC): SFC is focused on the design of MIMO control structures. Its basic principle is concerned about the explicit design of the multi-variable state-feedback controllers according to some predefined performance measures [79]. Such measures can be defined in multitude of ways, i.e. using norms for selected signals or specifying a priori robustness in the design of the control gains. The most commonly used norms are $\mathrm{H}_{2}$ and $H_{\infty}$. These measures are defined as a mathematical optimization problem, the solution of which yields the optimal feedback gains $K$.

As a simple example, the design of the SFC to shape the frequency response of the VSC is as follows:

$$
\begin{gathered}
L(j \omega, \rho)=G(j \omega) K(j \omega, \rho) \\
L_{D}(s)=\left[\begin{array}{cc}
\omega_{d} & 0 \\
0 & \omega_{d}
\end{array}\right] \\
\min \left\|L(\rho)-L_{D}(s)\right\|^{2}
\end{gathered}
$$

where $L(j \omega, \rho)$ is the open-loop frequency response of the plant that is defined by physical model for the plant $G(j \omega)$ and control gains $K . L_{D}(s)$ is desired frequency response of the open-loop plant, which is obtained by optimizing the norm.

In general, when SFC is applied to power converters, the overall control is embedded into a single structure and it is invariably implemented as an indirect control by using a modulator stage. For intance, Fig. 7 shows a SFC applied to a grid-feeding VSC. A well-known issue with SFC is that it 


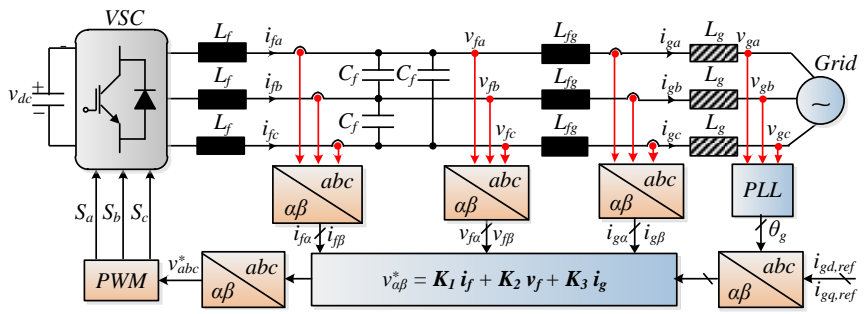

Fig. 7. SFC MIMO structure for a grid-feeding VSC with LCL filter [8].

is difficult to analytically impose constraints within the design process. To solve this problem, researchers have experimented with different types of numerical control algorithms such as linear-matrix-inequalities (LMIs). For instance, this method was used in [6], where the objective was to design a statefeedback controller for the grid-tied VSC with an LCL filter with respect to constraints, as well as guaranteed robustness to grid inductance parameter variations and transient response. Another example is reported in [7], again for the application of grid-tied VSC with an LCL filter, where the main reason for using the state-feedback instead of cascaded loops was that both current control and active damping can be inherently embedded within the one single control formulation. Similar ideas have been applied also in conditions where the grid is distorted [8].

The general theory for calculation of optimal gains in SFC with predetermined stability and robustness is well established. Once these gains are calculated and implemented, the controller generally exhibits very low computational burden. However, the main objection for using SFC in practical VSC applications is that high level of theoretical expertise is required to successfully carry out such optimal design, despite the fact that general theory to quantify and design for desired stability and robustness is well established.

2) Sliding Mode Control (SMC): SMC is a popular category of advanced controllers that is characterized by its inherent compatibility with variable structure systems such as power electronic converters. The basic principle behind the SMC is to define one or more sliding surfaces that specify the performance objectives of the system. Then, it designs a discontinuous feedback control that forces the system states to reach the sliding surface in finite time [80]. Typical sliding surface functions are based on linear combination of various signals from the VSC control system such as the current error and its derivative, the output capacitor filter voltage error and its derivative, as well as integrals and derivatives of estimated current and voltages. Therefore, it allows one to naturally design a MIMO control structure. A simple example of a sliding surface to control only two state variables, $\bar{x}_{1}$ and $\bar{x}_{2}$, can be defined as:

$$
\begin{gathered}
\bar{e}_{1}=\bar{x}_{1}^{*}-\bar{x}_{1} \\
\bar{e}_{2}=\bar{x}_{2}^{*}-\bar{x}_{2} \\
\bar{S}=K_{1} \bar{e}_{1}+K_{2} \bar{e}_{2}
\end{gathered}
$$

where $\bar{x}_{1}^{*}$ and $\bar{x}_{2}^{*}$ are the reference values. The errors of the selected state variables, $\bar{e}_{1}$ and $\bar{e}_{2}$ are used to define the sliding surface $\bar{S}$ and $K_{1}$ and $K_{2}$ are weighting factors that regulate the importance of specific parts in $\bar{S}$.

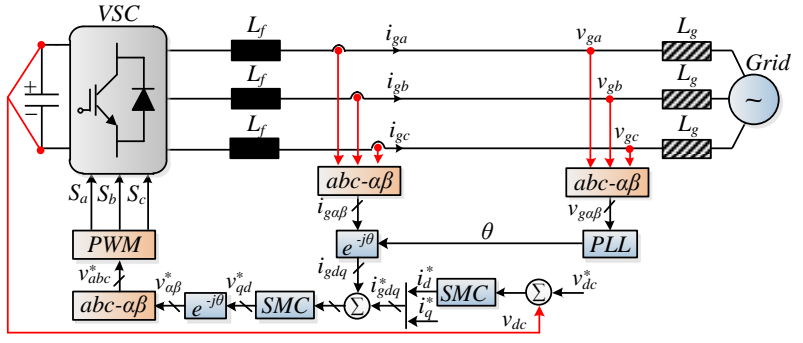

Fig. 8. Application of SMC in a cascaded control structure for a Grid-feeding VSC with L filter [10].

Well established Lyapunov stability theory is recognized as the most useful approach for analyzing the stability of an SMC system [81]. Computational complexity of the method depends on the complexity of sliding surface. For instance, if the VSC is interfaced to the grid only via $L$ filter, there is no need to introduce resonance damping in the sliding surface and the computational complexity is low. However, if VSC is interfaced through an $L C L$ filter, the sliding surface formation should be done in such a way that the resonance can be damped efficiently at the expense of increased cost and controller complexity [12].

SMC can be implemented with or without the modulator [9]. In the latter case, higher bandwidth can be achieved but it suffers of chattering problem that needs to be considered in the design process. As key characteristics, SMC has the capability to handle the system nonlinearities and it presents low dependence on the system parameters and external disturbances. Therefore, SMC can be categorized as highly robust to parameter uncertainty. Another advantage of the SMC compared to other advanced controllers is its capability to reduce the order of the plant, which largely simplifies the design procedure and analysis. This is especially useful when it is put in the cascade with linear controllers [11], [12]. In contrast, a disadvantage of SMC is that it is difficult to impose constraints or to regulate abstract quantities. For instance, the switching frequency when it is implemented as a direct control.

An illustrative application of SMC replacing one by one the linear controllers in a cascaded structure is shown in Fig. 8. It deploys an extended state observer plus a second order SMC (SOMSC) to control the dc-link capacitor voltage as the outer control loop and a SOSMC for the ac current control in the inner control [10].

3) Model Predictive Control (MPC): MPC strategy consists of designing an optimal problem which is based on three key elements, namely the prediction model, the cost function and the optimization algorithm [82]. In MPC, the desired system behavior is described using a cost function. Mainly, the cost function compares up to a certain prediction horizon, $N_{p}$, predicted state variables, $\bar{x}^{p}$, with reference values for these states. For instance, a simple cost function involving only two predicted state variables, $\bar{x}_{1}^{p}$ and $\bar{x}_{2}^{p}$, and a prediction horizon $N_{p}=1$, can be defined as follows:

$$
g_{\text {con }}=\left(\bar{x}_{1}^{*}(k+1)-\bar{x}_{1}^{p}(k+1)\right)^{2}+\lambda\left(\bar{x}_{2}^{*}(k+1)-\bar{x}_{2}^{p}(k+1)\right)^{2}
$$

where $\bar{x}_{1}^{*}$ and $\bar{x}_{2}^{*}$ are the command values and $\lambda$ is a weighting factor that regulates the importance of specific parts of the 
cost function. Larger values of $\lambda$ gives higher importance to a specific term.

Considereng (5), the prediction model can be defined as:

$$
\begin{gathered}
\bar{x}^{p}(k+1)=A_{d} \bar{x}(k)+B_{d} \bar{u}_{c}(k) \\
\bar{y}^{p}(k)=C_{d} \bar{x}^{p}(k)+D_{d} \bar{u}_{c}(k)
\end{gathered}
$$

where $\bar{y}^{P}$ are predicted outputs and $\bar{u}_{c}$ are inputs candidates. From (9), it can be stated that predicted state variables values depend on the input candidate $\bar{u}_{c}$. Therefore, each sampling instant the control action, $\bar{u}$, is decided as the input candidate that minimizes the cost function. To solve this optimal problem, an optimization algorithm is then needed.

Prediction model and cost function are unique for a given VSC topology and application [83]. On the other hand, optimization algorithm can be performed in different ways. Two main categories can be defined considering the type of the optimization problem. On one hand, continuous control set MPC (CCS-MPC) considers the input control vector candidate as a continuous control signal. Then, it solves a continuous optimization problem and the output can be any vector within the control region defined by available voltage vectors of VSC [84]. To synthesize the final control action, CCS-MPC uses any modulation strategy according to the VSC topology which ensures a constant switching frequency [85]. Therefore, CCSMPC belongs to the indirect control category. On the other hand, finite control set MPC (FCS-MPC) considers a set with limited number of input candidates. Then, it solves an integer optimization problem and the output can only be one of the vectors in the considered set [86]. Two main approaches are used to solve the optimal problem in FCS-MPC. The most common one is the exhaustive search algorithm (ESA) which computes the predicted states and evaluates the cost function for each vector in the candidates set [87]. The main problem of ESA is that computational burden increases with the number of candidates in the set. To solve this problem, the sphere decoding algorithm (SDA) has been proposed [88], [89]. SDA takes advantage of branch and bound techniques to avoid the evaluation of all the candidates in the set and find the optimal solution. In FCS-MPC, the final control action is the output vector selected by the optimal problem. Therefore, FCS-MPC belongs to the direct control category.

When CCS-MPC and FCS-MPC are compared, the latter allows one to achieve higher controller bandwidth. This is due to the direct control implementation principle. However, this leads to a variable switching frequency that can be avoided by using a CCS-MPC strategy. Methods that embed the modulators in the optimal problem design have also been proposed to capture the best features of the FCS-MPC and CCS-MPC algorithms, i.e. the constant switching frequency and excellent dynamic response [13]-[17]. FCS-MPC is also highly beneficial in high power applications, where minimization of the average switching frequency is generally an important requirement. To this end, the high sampling rate allows fine control fidelity and thus high power quality, while maintaining fast dynamics at the same time [90].

Key features of MPC are that the design of the optimal problem is highly intuitive, allowing one to integrate explicitly nonlinearities and consider system constraints in the problem

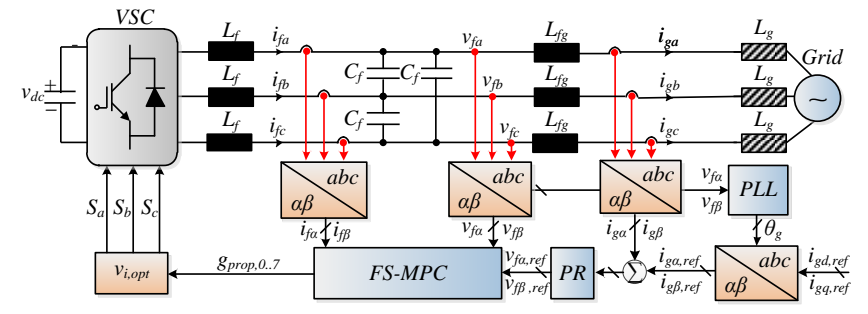

Fig. 9. Application of inner MPC algorithm in cascade with an outer conventional PR controller for grid-tied VSC with an LCL filter [77].

formulation. The latter one is a unique characteristic of MPC compared to other advanced control methods. It is therefore suitable for maintaining controllability of the converter in transient operating conditions, such as LVRT and HVRT [91]. In these applications, FCS-MPC strategy is used as a one-toone replacement of inner linear current controllers to achieve improved decoupling capability and better robustness to large signal disturbances. MPC also allows one to define a MIMO control structure to merge multiple control loops in a single stage. The procedure is simple and just consists of defining a suitable cost function. Applications of this type have been proved to yield both significantly better dynamic performance and robustness compared to cascaded linear control. For instance, it was shown that grid-tied VSCs with LCL filter can have an inherent active damping capability when controlled with MPC [92]. Moreover, significantly improved primary [44], [93] and secondary dynamic performance [94] has been reported in microgrids when MPC is used.

Lack of formal stability analysis methods for FSC-MPC has long been cited as a major disadvantage of this strategy. Although it is possible to find theoretical works, the scope is limited to particular applications [95], [96]. However, several promising approaches have recently been proposed to solve this issue. One is called statistical model checking (SMC) [97]. Here, the VSC and the controller are treated like timed automata, and their statistical performance is formally tested in various scenarios. While being very effective, this approach requires detailed knowledge about the tools from computer science community, which may not be easily accessible to electrical engineers. Another promising tool that has recently been applied is a describing function method [77]. Here, the frequency response of the VSC controlled via FCS-MPC is captured and plugged together with other controllers to construct the overall frequency response of the system and verify its robustness and stability [98]. An illustrative application of grid-tied VSC where outer loop is linear, while FCS-MPC is used in the inner loop to regulate the $L C$ filter voltage and provide active damping is shown in Fig. 9.

\section{B. Data Based Control}

Data based control is different to all the model based strategies in the sense that it is explicitly designed based on using the available input/output data to describe the controlled system. Data can be obtained either from the real system or from a model of the actual plant.

1) Artificial Neural Network (ANN) Control: In essence, ANN allows one to do a non-parametric function approxima- 
TABLE I

Model and Data Based Advanced Control Methods - An Overview

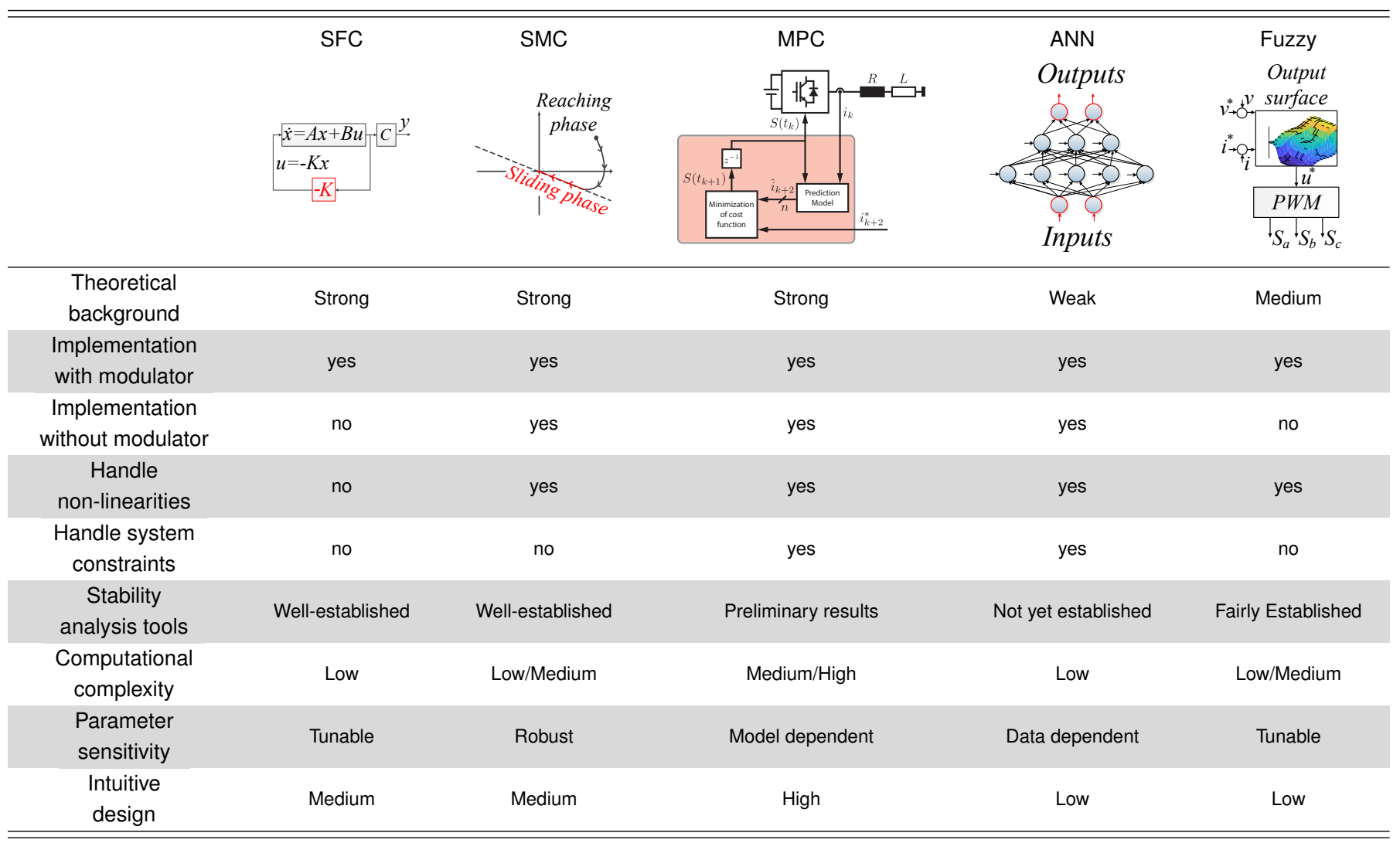

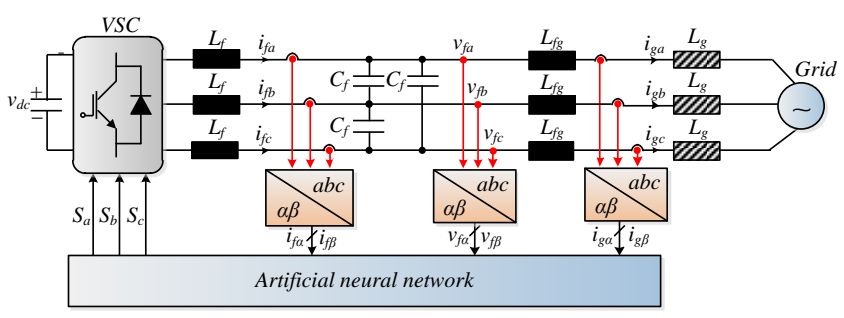

Fig. 10. Control imitation structure using an artificial neural network [99].

tion. It is comprised of an input layer, one or more hidden layers, and an output layer. Each of these layers contains a number of neurons that process the signals flow coming from neurons in the layer below. This simple structure only involves basic algebraic operations. For this reason, evaluation of ANN is generally very computationally light. Moreover, ANN can be trained to approximate any given nonlinear relationship between input and output data with arbitrary precision [100].

ANN can be implemented as a direct or indirect control. In addition, it can be used to replace one by one each linear controller in a cascaded structure or can be designed as a MIMO controller. For these reasons, researchers have applied ANNs in several areas of advanced control for power converters. For instance, in [23] the ANN structure is used instead of inner control loops of a grid-forming VSC. The output of the ANN is the VSC output voltage, which is finally synthesized by the modulator stage. The main idea here was to train a single ANN controller to learn the optimal actuation signal from a family of linear controllers, each optimally tuned for a specific loading condition. In this sense, ANN was shown to provide better global performance, as well as more robustness to disturbances than linear controllers. On the other hand, in [99], the neural network was trained to emulate the FCS-MPC controller and showed similar performance to original controller. Further on, in [101] innovative data-generation process and training procedures were used to experimentally validate the ANNbased emulator with excellent resemblance to original FCSMPC and very low computational complexity. This particular application is also depicted in the Fig. 10. Therefore, since ANN controllers are trained on data from original controllers or other sources, it can be stated that their robustness and stability features are dependent on the quality of data.

However, there is still no formally developed theory to directly verify these important performance metrics. This can be seen as a large drawback of ANN-based control. In addition, imposing constraints on the state variables is challenging when ANN is used in the inner control loops. To avoid the problems with imposing constraints, another prominent group of applications used conventional controllers in the inner control loops but implemented ANN to serve as a reference generator in the outer loops. An example of this approach was reported in [24], where the ANN was trained to be able to quickly extract the nonlinear load active and reactive power current components. These components were 
then used to create current references for the VSC, which are expected to achieve harmonic suppression and load balancing. The given current references are then controlled using the standard controllers.

Besides real-time control applications, ANNs have also been used for offline design of advanced controllers and systems. The key idea here is to firstly extract comprehensive input-output data that correlates relevant design parameters to performance metrics of the controlled system either from its simulation model or directly from the experimental setup. This data is used to train the ANN that serves as a fast surrogate model of the system. Such ANN-based model can finally be used for optimal design of either control or physical parameters of the system. This procedure was successfully deployed for tuning of weighting factors in the cost function of the FCS-MPC algorithm [25] and for optimal design for reliability of power electronic converters [26].

2) Fuzzy Control: Similarly as ANNs, fuzzy signal processing structures can also used to do function approximation. These rules can transform a certain set of inputs (e.g. the errors between the references and measured signals) into one or more outputs. The output can be used either as the control signal, or in a feedback loop. Fuzzy rules are sometimes implemented in the latent space, which means that fuzzification and defuzzification is required. The disadvantage of fuzzy controllers compared to ANNs is that rule derivation, although intuitive, is heuristic. Moreover, since rules are discrete, the overall approximated function has a non-smooth structure which leads to a weaker generalization capability than ANNs. On the other hand, fuzzy models can also be represented as a mixture of several linear models which are blended together using the membership functions [102]. These types of controllers are termed as Takagi-Sugeno (T-S) fuzzy controllers. Fairly well established advanced control design tools such as linear matrix inequalities can then be used to formally design the controller and prove the stability, which is a big advantage over ANN-based controllers. Moreover, fuzzy control systems can be explicitly designed to provide robustness to parameter uncertainty through introduction of additive bounded terms [103]. Due to their fragmented implementation, fuzzy controllers generally do not have a particularly high computational complexity, if they are well implemented [104].

Fuzzy controllers are implemented as an indirect control strategy by including the modulator stage. They can be used to replace one-to-one linear controllers. For instance, in [18] this approach was proposed to substitute current controller for a grid-feeding VSC. It is also possible to use a fuzzy controller to define a MIMO control structure like in [19]. Here, fuzzy controller was used to replace cascaded voltage and current controllers for the grid-forming VSC. Similar to ANN, it is difficult to handle constraints with fuzzy controllers. To avoid this problem, the same approach as for ANN is used. Basically, fuzzy controller is used as a supplementary control law to generate references for the main control loops that are designed by using conventional controllers [20].

Researchers have also combined application of fuzzy and ANN control in [21], [22]. The main motivation was to combine the best features of the two methods, i.e the intuitive fuzzy rules and smooth learning capability of ANNs. With this approach, the tuning of fuzzy rules is done in analytic fashion as opposed to conventional scenario where they are set using the trial and error. It was shown that the steady-state performance of the system can be significantly improved by this approach when compared to classical PI-based control.

\section{Experimental CASE Study}

In order to assess the performance of various control systems, a benchmark case study is established. While many different control structures are possible, only one representative case study was selected, i.e. voltage control of the $L C$ filtered VSC. There are several reasons why this particular structure has been selected for comparison tests. Firstly, the limitations of conventional cascaded controllers are fully evident here because the controlled system is of the second order and merging of controllers leads to clear speeding up of the response. Secondly, the quantitative performance metrics for voltage control on the standalone $L C$ filtered VSC are defined in the relevant standards (e.g. IEC 62040). Therefore, it is straightforward to make fair comparisons between different control methods. Lastly, grid-supporting VSC with voltage control on the $L C$ filter is the structure with the widest spectrum of control functionalities, and it is one of the most frequently used in the literature for grid-supporting VSCs [5], [32], [33], [36], [44].

DC link voltage in the setup was $v_{d c}=700 \mathrm{~V}, L C$-filter parameters are $L_{f}=2.4 \mathrm{mH}, C_{f}=15 \mu \mathrm{F}$. Reference voltage is $V_{r}^{R M S}=230 \mathrm{~V}, f_{r}=50 \mathrm{~Hz}$. Linear load is $R_{\text {load }}=33$ $\Omega$, while sampling times in the modulator and non-modulator based methods are $T_{s}=100 \mu \mathrm{s}$ and $T_{s}=20 \mu \mathrm{s}$, respectively. In all modulator based methods, uniformly sampled PWM with single update mode and leading-edge modulation was implemented, thereby resulting in fixed switching frequency equal to $1 / T_{s}=10 \mathrm{kHz}$. On the other hand, as their name suggests, non-modulator-based strategies do not have a modulator and in their case only the sampling frequency can be directly specified. As explained in detail in Section IV-A, due to specific switching process, the switching frequency in non-modulator based strategies does not have a fixed value and it is also not possible to directly specify it. On the contrary, it is only possible to indirectly control the average value of the switching frequency over some custom defined timewindow (e.g. by adjusting the weighting factor in the cost function) [25]. Therefore, to make a relatively fair performance comparison between different strategies, the weighting factors were manually tuned so that average switching frequency of non-modulator based methods is approximately equal to the fixed switching frequency of modulator based methods.

Based on implementation details described above, several control methods have been implemented and corresponding experimental results are shown in Fig. 11. Results for cascaded linear control, where controller gains were tuned using the methodology from [39], are shown in Fig. 11(a). On the other hand, several advanced control methods with and without modulator have been implemented. Particularly, for FCS-MPC, tuning methodology from [25] was followed. For non-modulator based ANN, data was extracted using the 


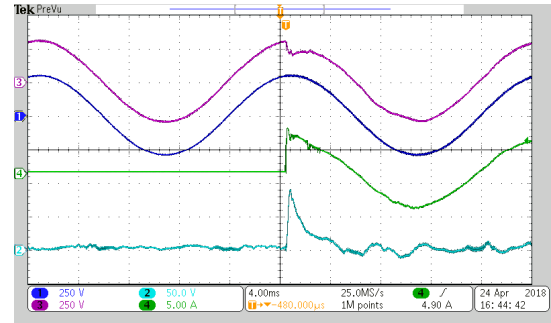

(a)

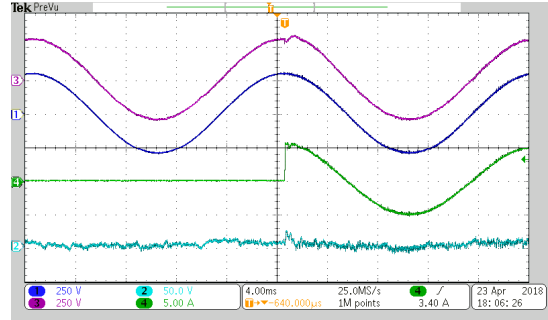

(b)

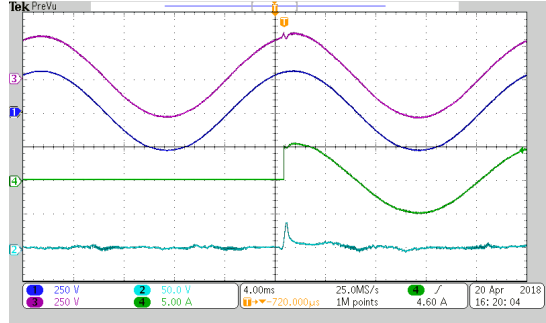

(c)

Fig. 11. Experimental comparison of conventional cascaded linear control and advanced control strategies on a case study involving standalone 2-level VSC: (a) Cascaded linear control with modulator. (b) State-feedback control without modulator. (c) State-feedback control with modulator.

model presented in [44] in the way described in [101]. For non-modulator based SMC, methodology from [9] has been followed. Sampling time for all these methods has been $T_{s}$ $=20 \mu \mathrm{s}$. Interestingly, there was no noticeable difference in performance between these non-modulator based strategies. Therefore only one result is presented in Fig. 11(b). Finally, for state-feedback control with dedicated modulator, several different methods have been tried out, including CCS-MPC [105], fuzzy control [106] and ANN control [23]. Again, as there was no noticeable difference between in the performance of these methods, only one result is presented in Fig. 11(c).

It can be seen that advanced control methods outperform cascaded linear control in terms of dynamic performance. In addition, non-modulator based strategies yield the best dynamics, but have higher switching ripple and larger steady-state error compared to the other two. Finally, the state-feedback controllers have only slightly worse dynamics compared, but excellent steady-state performance owing to the usage of the modulator. All these results are consistent with the analysis presented in Sections IV and V.

\section{INDUSTRIAL APPliCABILITy OF AdVANCED CONVERTER CONTROL}

So far, the paper has discussed qualitatively why and how can advanced control outperform classical cascaded linear control systems. It has also described a variety of advanced controllers and it was afterwards shown experimentally that they outperform conventional linear control. However, only a small difference in dynamic performance between various classes of non-modulator and modulator based advanced controllers was observed. For this reason, in this section no particular advanced control method is discussed, but its focus is on the general applicability of such control in practical industrial applications. Namely, advanced control often comes with drawbacks such as high implementation complexity, heavy computational burden that may require more expensive microprocessors, and problematic maintainability due to a need for highly skilled engineers. Thus, advantages and drawbacks need to be carefully accounted for to justify the implementation of advanced controllers in practice.

Obvious candidate applications of advanced controllers are the ones which require excellent large-signal performance and robustness to parameter uncertainty. One example are power converters exposed to frequent faults in the grid. Another example are power electronics based standalone microgrids that are exposed to pulsating loads. Such types of microgrids can often be seen in mission critical applications such as military installations where weapons and other electromagnetic loads present a challenging environment for linear controllers. Vehicular applications can also be seen as microgrids burdened with pulsed loads. Other candidate applications of advanced control are DG converters connected to weak grids where gridinterfacing impedance may widely vary. In this scenario, advanced control can be generally designed for higher robustness to parameter variations. On the other hand, in applications with continuous or slowly changing load/generation profile that are connected to strong grids (e.g. data centers, renewable energy plants), the disadvantages of advanced control generally outweigh the advantages. Therefore, there is generally no practical need to move away from very well understood conventional linear control in such applications. Nevertheless, it has recently been shown that certain types of advanced controllers can improve the thermal profile of power electronic converters even in completely static applications [107]. This may have a considerably positive impact on their reliability. However, more research needs to be done in this area.

To sum up, advanced control for power converters can increase the implementation complexity and lead to higher computational requirements. For this reason, the use of conventional linear cascaded control could be a good option when system requirements are not challenging. On the other hand, the cost and computational capabilities of hardware control platforms are not a major limitation anymore. Therefore, one can take advantage of using this hardware. Advanced control strategies for power converters can yield power conversion systems with better dynamic responses, increased efficiency and higher reliability. In addition, they are the right option when one is seeking to get the most from the power converter system. As a conclusion, the standpoint of authors is that these kinds of strategies have their place in practical industrial applications.

\section{CONCLUSIONS AND Future TRENDS}

This paper has presented the main roles of voltage source converters (VSCs) in distributed generation (DG) systems and microgrids. The conventional cascaded linear control structure has been described first, and its main limitations have been analyzed. In short, these disadvantages are related to the use of the modulator stage, the separation principle due to the cascaded structure and the inability to handle large disturbances, nonlinearities and parameter variations. It has been concluded that these drawbacks can be reduced by exploiting advanced control strategies. Paper has afterwards overviewed 
and experimentally compared several prominent model-based and data-based advanced control strategies. Possibilities for their practical applications have also been discussed.

Future trends on advanced control strategies for VSCs in DG and microgrids will include the development of new methods that do not rely on the modulator, but are able to yield constant switching frequencies. The aim of this research is to maximize the dynamic performance of VSCs, but have predictable switching patterns at the same time to ease the output filter design. Another prominent research area will be the development of controllers that achieve high dynamic performance with reduced number of sensors, as this can greatly improve their cost-effectiveness and reliability. Finally, a more disruptive future research topic is about data-based methods that can either be trained autonomously or to imitate known controllers that may be computationally too heavy for real-time execution.

\section{REFERENCES}

[1] H. Sugimoto, S. Morimoto, and M. Yano, "A high performance control method of a voltage-type pwm converter," in PESC '88 Record., 19th Annual IEEE Power Electronics Specialists Conference, pp. 360-368 vol.1, April 1988.

[2] J. Rocabert, A. Luna, F. Blaabjerg, and P. Rodríguez, "Control of power converters in ac microgrids," IEEE Trans. on Power Electron., vol. 27, pp. 4734-4749, Nov 2012.

[3] L. Harnefors, X. Wang, A. G. Yepes, and F. Blaabjerg, "Passivitybased stability assessment of grid-connected VSCs-an overview," IEEE Journal of Emerging and Selected Topics in Power Electronics, vol. 4, pp. 116-125, March 2016.

[4] W. Wu, Y. Liu, Y. He, H. S. Chung, M. Liserre, and F. Blaabjerg, "Damping methods for resonances caused by lcl-filter-based currentcontrolled grid-tied power inverters: An overview," IEEE Trans. on Ind. Electron., vol. 64, pp. 7402-7413, Sep. 2017.

[5] J. M. Guerrero, J. C. Vasquez, J. Matas, L. G. de Vicuna, and M. Castilla, "Hierarchical control of droop-controlled ac and dc microgrids-a general approach toward standardization," IEEE Trans. on Ind. Electron., vol. 58, pp. 158-172, Jan 2011.

[6] L. A. Maccari, J. R. Massing, L. Schuch, C. Rech, H. Pinheiro, R. C. L. F. Oliveira, and V. F. Montagner, "LMI-based control for gridconnected converters with lcl filters under uncertain parameters," IEEE Trans. on Power Electron., vol. 29, pp. 3776-3785, July 2014.

[7] M. S. Sadabadi, A. Haddadi, H. Karimi, and A. Karimi, "A robust active damping control strategy for an lcl-based grid-connected $\mathrm{dg}$ unit," IEEE Trans. on Ind. Electron., vol. 64, pp. 8055-8065, Oct 2017.

[8] N. Lai and K. Kim, "Robust control scheme for three-phase gridconnected inverters with lcl-filter under unbalanced and distorted grid conditions," IEEE Trans. on Energy Conversion, vol. 33, pp. 506-515, June 2018.

[9] R. Guzman, L. G. de Vicuña, J. Morales, M. Castilla, and J. Matas, "Sliding-mode control for a three-phase unity power factor rectifier operating at fixed switching frequency," IEEE Trans. on Power Electron., vol. 31, pp. 758-769, Jan 2016.

[10] J. Liu, S. Vazquez, L. Wu, A. Marquez, H. Gao, and L. G. Franquelo, "Extended state observer-based sliding-mode control for three-phase power converters," IEEE Trans. on Ind. Electron., vol. 64, pp. 22-31, Jan 2017.

[11] R. P. Vieira, L. T. Martins, J. R. Massing, and M. Stefanello, "Sliding mode controller in a multiloop framework for a grid-connected VS with lcl filter," IEEE Trans. on Ind. Electron., vol. 65, pp. 4714-4723, June 2018.

[12] N. Altin, S. Ozdemir, H. Komurcugil, and I. Sefa, "Sliding-mode control in natural frame with reduced number of sensors for threephase grid-tied lcl-interfaced inverters," IEEE Trans. on Ind. Electron., vol. 66, pp. 2903-2913, April 2019.

[13] L. Tarisciotti, P. Zanchetta, A. Watson, J. C. Clare, M. Degano, and S. Bifaretti, "Modulated model predictive control for a three-phase active rectifier," IEEE Trans. on Ind. Appl., vol. 51, pp. 1610-1620, March 2015.
[14] S. Vazquez, A. Marquez, R. Aguilera, D. Quevedo, J. I. Leon, and L. G. Franquelo, "Predictive optimal switching sequence direct power control for grid-connected power converters," IEEE Trans. on Ind. Electron., vol. 62, pp. 2010-2020, April 2015.

[15] S. Vazquez, P. Acuna, R. P. Aguilera, J. Pou, J. I. Leon, and L. G. Franquelo, "Dc-link voltage balancing strategy based on optimal switching sequences model predictive control for single-phase h-npc converters," IEEE Trans. on Ind. Electron., pp. 1-1, 2019.

[16] I. M. Hassine, M. W. Naouar, and N. Mrabet-Bellaaj, "Model predictive-sliding mode control for three-phase grid-connected converters," IEEE Trans. on Ind. Electron., vol. 64, pp. 1341-1349, Feb 2017.

[17] F. Sebaaly, H. Vahedi, H. Y. Kanaan, and K. Al-Haddad, "Novel current controller based on MPC with fixed switching frequency operation for a grid-tied inverter," IEEE Trans. on Ind. Electron., vol. 65, pp. 61986205, Aug 2018

[18] M. A. Hannan, Z. A. Ghani, A. Mohamed, and M. N. Uddin, "Realtime testing of a fuzzy-logic-controller-based grid-connected photovoltaic inverter system," IEEE Trans. on Ind. Appl., vol. 51, pp. 47754784, Nov 2015.

[19] C. Tao, C. Wang, and C. Chang, "A design of a dc-ac inverter using a modified ZVS-PWM auxiliary commutation pole and a DSP-based pid-like fuzzy control," IEEE Trans. on Ind. Electron., vol. 63, pp. 397405, Jan 2016

[20] N. L. Diaz, T. Dragičević, J. C. Vasquez, and J. M. Guerrero, "Intelligent distributed generation and storage units for dc microgrids-a new concept on cooperative control without communications beyond droop control," IEEE Trans. on Smart Grid, vol. 5, pp. 2476-2485, Sep. 2014

[21] R. Wai, M. Chen, and Y. Liu, "Design of adaptive control and fuzzy neural network control for single-stage boost inverter," IEEE Trans. on Ind. Electron., vol. 62, pp. 5434-5445, Sep. 2015.

[22] F. Lin, K. Lu, T. Ke, B. Yang, and Y. Chang, "Reactive power control of three-phase grid-connected pv system during grid faults using takagisugeno-kang probabilistic fuzzy neural network control," IEEE Trans. on Ind. Electron., vol. 62, pp. 5516-5528, Sep. 2015.

[23] X. Sun, D. Xu, F. H. F. Leung, Y. Wang, and Y.-S. Lee, "Design and implementation of a neural-network-controlled ups inverter," in IECON'99. Conference Proceedings. 25th Annual Conference of the IEEE Ind. Electron Society (Cat. No.99CH37029), vol. 2, pp. 779-784 vol.2, Nov 1999.

[24] B. Singh and S. R. Arya, "Back-propagation control algorithm for power quality improvement using dstatcom," IEEE Trans. on Ind. Electron., vol. 61, pp. 1204-1212, March 2014.

[25] T. Dragičević and M. Novak, "Weighting factor design in model predictive control of power electronic converters: An artificial neural network approach," IEEE Trans. on Ind. Electron., pp. 1-1, 2018.

[26] T. Dragičević, P. Wheeler, and F. Blaabjerg, "Artificial intelligence aided automated design for reliability of power electronic systems," IEEE Trans. on Power Electron., vol. 34, pp. 7161-7171, Aug 2019.

[27] H. Han, X. Hou, J. Yang, J. Wu, M. Su, and J. M. Guerrero, "Review of power sharing control strategies for islanding operation of ac microgrids," IEEE Trans. on Smart Grid, vol. 7, pp. 200-215, Jan 2016

[28] Y. Han, H. Li, P. Shen, E. A. A. Coelho, and J. M. Guerrero, "Review of active and reactive power sharing strategies in hierarchical controlled microgrids," IEEE Trans. on Power Electron., vol. 32, pp. 2427-2451, March 2017.

[29] T. Dragičević, X. Lu, J. C. Vasquez, and J. M. Guerrero, "Dc microgrids - part i: A review of control strategies and stabilization techniques," IEEE Transactions on Power Electronics, vol. 31, no. 7, pp. 4876-4891, 2016

[30] T. Dragičević, X. Lu, J. C. Vasquez, and J. M. Guerrero, "Dc microgrids - part ii: A review of power architectures, applications, and standardization issues," IEEE Transactions on Power Electronics, vol. 31, no. 5, pp. 3528-3549, 2016

[31] J. Matevosyan, B. Badrzadeh, T. Prevost, E. Quitmann, D. Ramasubramanian, H. Urdal, S. Achilles, J. MacDowell, S. H. Huang, V. Vital, J. O'Sullivan, and R. Quint, "Grid-forming inverters: Are they the key for high renewable penetration?," IEEE Power and Energy Magazine, vol. 17, pp. 89-98, Nov 2019.

[32] Q. Zhong and G. Weiss, "Synchronverters: Inverters that mimic synchronous generators," IEEE Trans. on Ind. Electron., vol. 58, pp. 12591267, April 2011.

[33] S. D'Arco, J. A. Suul, and O. B. Fosso, "A virtual synchronous machine implementation for distributed control of power converters in smartgrids," Electric Power Systems Research, vol. 122, pp. 180 $197,2015$. 
[34] A. Camacho, M. Castilla, J. Miret, R. Guzman, and A. Borrell, "Reactive power control for distributed generation power plants to comply with voltage limits during grid faults," IEEE Trans. on Power Electron., vol. 29, pp. 6224-6234, Nov 2014.

[35] L. Zhang, L. Harnefors, and H. Nee, "Power-synchronization control of grid-connected voltage-source converters," IEEE Trans. on Power Systems, vol. 25, pp. 809-820, May 2010.

[36] J. Liu, Y. Miura, and T. Ise, "Comparison of dynamic characteristics between virtual synchronous generator and droop control in inverterbased distributed generators," IEEE Trans. on Power Electron., vol. 31 pp. 3600-3611, May 2016.

[37] P. Rodríguez, C. Citro, J. I. Candela, J. Rocabert, and A. Luna, "Flexible grid connection and islanding of spc-based pv power converters," IEEE Trans. on Ind. Appl., vol. 54, pp. 2690-2702, May 2018.

[38] R. Teodorescu, M. Liserre, and P. Rodriguez, Grid Converters for Photovoltaic and Wind Power Systems. Wiley-IEEE Press, December 2010.

[39] F. de Bosio, L. A. de Souza Ribeiro, F. D. Freijedo, M. Pastorelli, and J. M. Guerrero, "Effect of state feedback coupling and system delays on the transient performance of stand-alone vsi with lc output filter,' IEEE Trans. on Ind. Electron., vol. 63, pp. 4909-4918, Aug 2016.

[40] W. Zhang, J. Rocabert, J. I. Candela, and P. Rodriguez, "Synchronous power control of grid-connected power converters under asymmetrical grid fault," Energies, vol. 10, no. 7, 2017.

[41] J. M. Guerrero, Luis Garcia de Vicuna, J. Matas, M. Castilla, and J. Miret, "Output impedance design of parallel-connected ups inverters with wireless load-sharing control," IEEE Trans. on Ind. Electron., vol. 52, pp. 1126-1135, Aug 2005 .

[42] L. Lu and C. Chu, "Consensus-based secondary frequency and voltage droop control of virtual synchronous generators for isolated ac microgrids," IEEE Journal on Emerging and Selected Topics in Circuits and Systems, vol. 5, pp. 443-455, Sep. 2015.

[43] O. Mo, S. D'Arco, and J. A. Suul, "Evaluation of virtual synchronous machines with dynamic or quasi-stationary machine models," IEEE Trans. on Ind. Electron., vol. 64, pp. 5952-5962, July 2017.

[44] T. Dragičević, "Model predictive control of power converters for robust and fast operation of ac microgrids," IEEE Trans. on Power Electron. vol. 33, pp. 6304-6317, July 2018.

[45] D. N. Zmood and D. G. Holmes, "Stationary frame current regulation of pwm inverters with zero steady-state error," IEEE Trans. on Power Electron., vol. 18, pp. 814-822, May 2003.

[46] S. Vazquez, J. I. Leon, J. M. Carrasco, L. G. Franquelo, E. Galvan, M. Reyes, J. A. Sanchez, and E. Dominguez, "Analysis of the power balance in the cells of a multilevel cascaded h-bridge converter," IEEE Trans. on Ind. Electron., vol. 57, pp. 2287-2296, July 2010.

[47] D. Shin, K. Lee, J. Lee, D. Yoo, and H. Kim, "Implementation of fault ride-through techniques of grid-connected inverter for distributed energy resources with adaptive low-pass notch pll," IEEE Trans. on Power Electron., vol. 30, pp. 2859-2871, May 2015.

[48] Y. Tang, P. C. Loh, P. Wang, F. H. Choo, and F. Gao, "Exploring inherent damping characteristic of lcl-filters for three-phase gridconnected voltage source inverters," IEEE Trans. on Power Electron., vol. 27, pp. 1433-1443, March 2012

[49] S. G. Parker, B. P. McGrath, and D. G. Holmes, "Regions of active damping control for lcl filters," IEEE Trans. on Ind. Appl., vol. 50, pp. 424-432, Jan 2014

[50] R. Peña-Alzola, M. Liserre, F. Blaabjerg, R. Sebastián, J. Dannehl, and F. W. Fuchs, "Analysis of the passive damping losses in lcl-filter-based grid converters," IEEE Trans. on Power Electron., vol. 28, pp. 2642 2646, June 2013

[51] M. P. Kazmierkowski and L. Malesani, "Current control techniques for three-phase voltage-source pwm converters: a survey," IEEE Trans. on Ind. Electron., vol. 45, pp. 691-703, Oct 1998.

[52] "IEEE standard for interconnection and interoperability of distributed energy resources with associated electric power systems interfaces," IEEE Std 1547-2018 (Revision of IEEE Std 1547-2003), pp. 1-138, April 2018.

[53] D. G. Holmes, T. A. Lipo, B. P. McGrath, and W. Y. Kong, "Optimized design of stationary frame three phase ac current regulators," IEEE Trans. on Power Electron., vol. 24, pp. 2417-2426, Nov 2009.

[54] A. Camacho, M. Castilla, J. Miret, L. G. de Vicuña, and G. L. Miguel Andrés, "Control strategy for distribution generation inverters to maximize the voltage support in the lowest phase during voltage sags," IEEE Trans. on Ind. Electron., vol. 65, pp. 2346-2355, March 2018.

[55] T. Tran, T. Chun, H. Lee, H. Kim, and E. Nho, "Pll-based seamless transfer control between grid-connected and islanding modes in grid-connected inverters," IEEE Trans. on Power Electron., vol. 29, pp. 5218-5228, Oct 2014.

[56] D. S. Ochs, B. Mirafzal, and P. Sotoodeh, "A method of seamless transitions between grid-tied and stand-alone modes of operation for utility-interactive three-phase inverters," IEEE Trans. on Ind. Appl., vol. 50, pp. 1934-1941, May 2014

[57] X. Li, H. Zhang, M. B. Shadmand, and R. S. Balog, "Model predictive control of a voltage-source inverter with seamless transition between islanded and grid-connected operations," IEEE Trans. on Ind. Electron., vol. 64, pp. 7906-7918, Oct 2017.

[58] P. C. Loh and D. G. Holmes, "Analysis of multiloop control strategies for $1 \mathrm{c} / \mathrm{cl} / \mathrm{lcl}$-filtered voltage-source and current-source inverters," IEEE Trans. on Ind. Appl., vol. 41, pp. 644-654, March 2005.

[59] Y. W. Li, "Control and resonance damping of voltage-source and current-source converters with $L C$ filters," IEEE Trans. on Ind. Electron., vol. 56, pp. 1511-1521, May 2009.

[60] "IEC standard for uninterruptible power systems (UPS) - part 3: Method of specifying the performance and test requirements," IEC 62040-3:2011, pp. 1-214, March 2011.

[61] X. Wang, Y. W. Li, F. Blaabjerg, and P. C. Loh, "Virtual-impedancebased control for voltage-source and current-source converters," IEEE Trans. on Power Electron., vol. 30, pp. 7019-7037, Dec 2015.

[62] J. He and Y. W. Li, "Analysis, design, and implementation of virtual impedance for power electronics interfaced distributed generation," IEEE Trans. on Ind. Appl., vol. 47, pp. 2525-2538, Nov 2011.

[63] V. Kaura and V. Blasko, "Operation of a phase locked loop system under distorted utility conditions," IEEE Trans. on Ind. Appl., vol. 33 pp. 58-63, Jan 1997.

[64] B. Wen, D. Dong, D. Boroyevich, R. Burgos, P. Mattavelli, and Z. Shen, "Impedance-based analysis of grid-synchronization stability for threephase paralleled converters," IEEE Trans. on Power Electron., vol. 31, pp. 26-38, Jan 2016.

[65] P. Rodriguez, J. Pou, J. Bergas, J. I. Candela, R. P. Burgos, and D. Boroyevich, "Decoupled double synchronous reference frame pll for power converters control," IEEE Trans. on Power Electron., vol. 22, pp. 584-592, March 2007.

[66] P. Rodriguez, A. Luna, I. Candela, R. Mujal, R. Teodorescu, and F. Blaabjerg, "Multiresonant frequency-locked loop for grid synchronization of power converters under distorted grid conditions," IEEE Trans. on Ind. Electron., vol. 58, pp. 127-138, Jan 2011.

[67] S. Vazquez, J. A. Sanchez, M. R. Reyes, J. I. Leon, and J. M. Carrasco, "Adaptive vectorial filter for grid synchronization of power converters under unbalanced and/or distorted grid conditions," IEEE Trans. on Ind. Electron., vol. 61, pp. 1355-1367, March 2014.

[68] A. Luna, J. Rocabert, J. I. Candela, J. R. Hermoso, R. Teodorescu, F. Blaabjerg, and P. Rodríguez, "Grid voltage synchronization for distributed generation systems under grid fault conditions," IEEE Trans. on Ind. Appl., vol. 51, pp. 3414-3425, July 2015.

[69] S. Golestan, J. M. Guerrero, and J. C. Vasquez, "Three-phase plls: A review of recent advances," IEEE Trans. on Power Electron., vol. 32, pp. 1894-1907, March 2017.

[70] Q. Zhong, P. Nguyen, Z. Ma, and W. Sheng, "Self-synchronized synchronverters: Inverters without a dedicated synchronization unit," IEEE Trans. on Power Electron., vol. 29, pp. 617-630, Feb 2014.

[71] P. Tielens and D. V. Hertem, "The relevance of inertia in power systems," Renewable and Sustainable Energy Reviews, vol. 55, pp. 999 - 1009, 2016.

[72] I. Serban and C. Marinescu, "Control strategy of three-phase battery energy storage systems for frequency support in microgrids and with uninterrupted supply of local loads," IEEE Trans. on Power Electron., vol. 29, pp. 5010-5020, Sep. 2014.

[73] S. Kouro, M. Malinowski, K. Gopakumar, J. Pou, L. G. Franquelo, B. Wu, J. Rodriguez, M. A. Perez, and J. I. Leon, "Recent advances and industrial applications of multilevel converters," IEEE Trans. on Ind. Electron., vol. 57, pp. 2553-2580, Aug 2010.

[74] S. Buso and P. Mattavelli, Digital Control in Power Electronics. Morgan \& Claypool, 2006.

[75] J. Y. Hung, W. Gao, and J. C. Hung, "Variable structure control: a survey," IEEE Trans. on Ind. Electron., vol. 40, pp. 2-22, Feb 1993.

[76] D. Liberzon and A. S. Morse, "Basic problems in stability and design of switched systems," IEEE Control Systems Magazine, vol. 19, pp. 5970, Oct 1999.

[77] T. Dragičević, C. Zheng, J. Rodriguez, and F. Blaabjerg, "Robust quasipredictive control of $l c l$-filtered grid converters," IEEE Trans. on Power Electron., vol. 35, no. 2, pp. 1934-1946, 2020. 
[78] M. Liserre, F. Blaabjerg, and S. Hansen, "Design and control of an lcl-filter-based three-phase active rectifier," IEEE Trans. on Ind. Appl., vol. 41, pp. 1281-1291, Sep. 2005.

[79] S. Skogestad and I. Postlethwaite, Multivariable feedback control: analysis and design. USA: Wiley, September 2005.

[80] V. Utkin, "Variable structure systems with sliding modes," IEEE Trans. on Automatic Control, vol. 22, pp. 212-222, April 1977.

[81] F. Bagheri, H. Komurcugil, O. Kukrer, N. Guler, and S. Bayhan, "Multi-input multi-output based sliding-mode controller for singlephase quasi-z-source inverters," IEEE Trans. on Ind. Electron., pp. 1-1, 2019.

[82] S. Vazquez, J. Rodriguez, M. Rivera, L. G. Franquelo, and M. Norambuena, "Model predictive control for power converters and drives: Advances and trends," IEEE Trans. on Ind. Electron., vol. 64, pp. 935947, Feb 2017.

[83] S. Vazquez, J. I. Leon, L. G. Franquelo, J. Rodriguez, H. A. Young, A. Marquez, and P. Zanchetta, "Model predictive control: A review of its applications in power electronics," IEEE Ind. Electron. Magazine, vol. 8, pp. 16-31, March 2014.

[84] S. Vazquez, C. Montero, C. Bordons, and L. G. Franquelo, "Model predictive control of a vsi with long prediction horizon," in 2011 IEEE International Symposium on Ind. Electron, pp. 1805-1810, June 2011.

85] J. I. Leon, S. Kouro, L. G. Franquelo, J. Rodriguez, and B. Wu, "The essential role and the continuous evolution of modulation techniques for voltage-source inverters in the past, present, and future power electronics," IEEE Trans. on Ind. Electron., vol. 63, pp. 2688-2701, May 2016.

[86] J. Rodriguez, M. P. Kazmierkowski, J. R. Espinoza, P. Zanchetta, H. Abu-Rub, H. A. Young, and C. A. Rojas, "State of the art of finite control set model predictive control in power electronics," IEEE Trans. on Ind. Inf., vol. 9, pp. 1003-1016, May 2013.

[87] P. Cortes, G. Ortiz, J. I. Yuz, J. Rodriguez, S. Vazquez, and L. G Franquelo, "Model predictive control of an inverter with output $L C$ filter for UPS applications," IEEE Trans. on Ind. Electron., vol. 56, pp. 1875-1883, June 2009.

[88] T. Geyer and D. E. Quevedo, "Multistep finite control set model predictive control for power electronics," IEEE Trans. on Power Electron. vol. 29, pp. 6836-6846, Dec 2014.

[89] R. Baidya, R. P. Aguilera, P. Acuña, S. Vazquez, and H. d. T. Mouton, "Multistep model predictive control for cascaded h-bridge inverters: Formulation and analysis," IEEE Trans. on Power Electron., vol. 33, pp. 876-886, Jan 2018

[90] T. Geyer and D. E. Quevedo, "Performance of multistep finite control set model predictive control for power electronics," IEEE Trans. on Power Electron., vol. 30, pp. 1633-1644, March 2015.

[91] V. Yaramasu, B. Wu, S. Alepuz, and S. Kouro, "Predictive control for low-voltage ride-through enhancement of three-level-boost and npcconverter-based pmsg wind turbine," IEEE Trans. on Ind. Electron. vol. 61, pp. 6832-6843, Dec 2014.

[92] N. Panten, N. Hoffmann, and F. W. Fuchs, "Finite control set model predictive current control for grid-connected voltage-source converters with LCL filters: A study based on different state feedbacks," IEEE Trans. on Power Electron., vol. 31, pp. 5189-5200, July 2016.

[93] T. Dragičević, "Dynamic stabilization of dc microgrids with predictive control of point-of-load converters," IEEE Trans. on Power Electron. vol. 33, pp. 10872-10884, Dec 2018.

[94] R. Heydari, T. Dragičević, and F. Blaabjerg, "High-bandwidth secondary voltage and frequency control of VSC-based ac microgrid," IEEE Trans. on Power Electron., pp. 1-1, 2019.

[95] R. P. Aguilera and D. E. Quevedo, "Stability analysis of quadratic mpc with a discrete input alphabet," IEEE Trans. on Automatic Control, vol. 58, no. 12, pp. 3190-3196, 2013.

[96] R. P. Aguilera and D. E. Quevedo, "Predictive control of power converters: Designs with guaranteed performance," IEEE Trans. on Ind. Inf., vol. 11, no. 1, pp. 53-63, 2015.

[97] M. Novak, U. M. Nyman, T. Dragičević, and F. Blaabjerg, "Statistical model checking for finite-set model predictive control converters: A tutorial on modeling and performance verification," IEEE Ind. Electron. Mag., vol. 13, no. 3, pp. 6-15, 2019

[98] J. Slotine and W. Li, Applied Nonlinear Control. Prentice Hall, 1991.

[99] I. S. Mohamed, S. Rovetta, T. D. Do, T. Dragičević, and A. A. Z Diab, "A neural-network-based model predictive control of three-phase inverter with an output $l c$ filter," IEEE Access, vol. 7, pp. 124737124749, 2019.

[100] K. Hornik, M. Stinchcombe, and H. White, "Multilayer feedforward networks are universal approximators," Neural Networks, vol. 2, no. 5, pp. $359-366,1989$
[101] M. Novak and T. Dragičević, "Supervised imitation learning of finite set model predictive control systems for power electronics," IEEE Trans. on Ind. Electron., pp. 1-1, 2020.

[102] N. Harrabi, M. Souissi, A. Aitouche, and M. Chaabane, "Intelligent control of grid-connected ac-dc-ac converters for a wecs based on t-s fuzzy interconnected systems modelling," IET Power Electronics, vol. 11, no. 9, pp. 1507-1518, 2018.

[103] N. Vafamand, M. H. Khooban, T. Dragičević, F. Blaabjerg, and J. Boudjadar, "Robust non-fragile fuzzy control of uncertain dc microgrids feeding constant power loads," IEEE Trans. on Power Electron., vol. 34, no. 11 , pp. $11300-11308,2019$

[104] N. Vafamand, M. H. Khooban, T. Dragičević, and F. Blaabjerg, "Networked fuzzy predictive control of power buffers for dynamic stabilization of dc microgrids," IEEE Trans. on Ind. Electron., vol. 66, no. 2, pp. 1356-1362, 2019.

[105] C. Zheng, T. Dragičević, B. Majmunović, and F. Blaabjerg, "Constrained modulated model-predictive control of an lc-filtered voltagesource converter," IEEE Trans. on Power Electron., vol. 35, pp. 19671977, Feb 2020.

[106] S. Choudhury, A. Choudhury, D. Panda, and P. K. Rout, "A contingen performance analysis of $\mathrm{m}$-flc using hbcc in an islanded microgrid," in ICPEICES 2016, pp. 1-6, July 2016

[107] M. Novak, V. N. Ferreira, M. Andresen, T. Dragičević, F. Blaabjerg, and M. Liserre, "Fs-mpc algorithm for optimized operation of a hybrid active neutral point clamped converter," in 2019 IEEE Energy Conversion Congress and Exposition (ECCE), pp. 1447-1453, Sep. 2019.

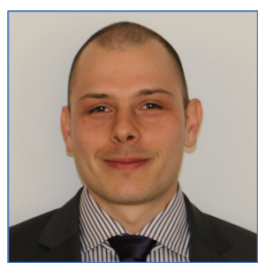

Tomislav Dragičević (S?09-M?13-SM?17) received the M.Sc. and the industrial Ph.D. degrees in Electrical Engineering from the Faculty of Electrical Engineering, University of Zagreb, Croatia, in 2009 and 2013, respectively. From 2013 until 2016 he has been a Postdoctoral researcher at Aalborg University, Denmark. From 2016 until 2020 he was an Associate Professor at Aalborg University, Denmark. From 2020 he is a Professor at the Technical University of Denmark.

His research interest is application of advanced control, optimization and artificial intelligence inspired techniques to provide innovative and effective solutions to emerging challenges in design, control and cyber-security of power electronics intensive electrical distribution systems and microgrids. He has authored and co-authored more than 200 technical publications (more than 100 of them are published in international journals, mostly in IEEE), 8 book chapters and a book in the field.

$\mathrm{He}$ serves as an Associate Editor in the IEEE TRANSACTIONS ON INDUSTRIAL ELECTRONICS, in IEEE TRANSACTIONS ON POWER ELECTRONICS, in IEEE Emerging and Selected Topics in Power Electronics and in IEEE Industrial Electronics Magazine. Dr. Dragičević is a recipient of the Končar prize for the best industrial PhD thesis in Croatia, a Robert Mayer Energy Conservation award, and he is a winner of an Alexander von Humbold fellowship for experienced researchers. 


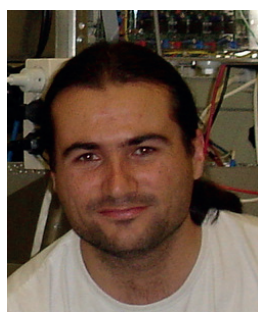

Sergio Vazquez (S'04-M'08-SM'14) was born in Seville, Spain, in 1974. He received the M.S. and $\mathrm{PhD}$ degrees in industrial engineering from the University of Seville (US) in 2006, and 2010, respectively.

Since 2002, he is with the Power Electronics Group working in $\mathrm{R} \& \mathrm{D}$ projects. He is an Associate Professor with the Department of Electronic Engineering, US. His research interests include powe electronics systems, modeling, modulation and control of power electronics converters applied to renewable energy technologies.

Dr. Vazquez was recipient as coauthor of the 2012 Best Paper Award of the IEEE Transactions on Industrial Electronics and 2015 Best Paper Award of the IEEE Industrial Electronics Magazine. He is involved in the Energy Storage Technical Committee of the IEEE industrial electronics society and is currently serving as an Associate Editor of the IEEE Transactions on Industrial Electronics.

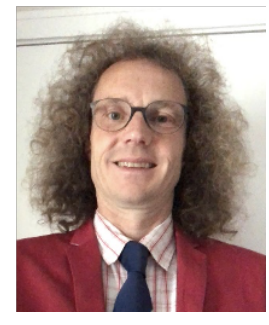

Pat Wheeler (SM?11) received his BEng [Hons] degree in 1990 from the University of Bristol, UK. $\mathrm{He}$ received his $\mathrm{PhD}$ degree in Electrical Engineering for his work on Matrix Converters from the University of Bristol, UK in 1994. In 1993 he moved to the University of Nottingham and worked as a research assistant in the Department of Electrical and Electronic Engineering. In 1996 he became a Lecturer in the Power Electronics, Machines and Control Group at the University of Nottingham, UK. Since January 2008 he has been a Full Professor in the same research group. He is currently Head of the Department of Electrica and Electronic Engineering at the University of Nottingham and the Li Dak Sum Chair Professor in Electrical and Aerospace Engineering at the University of Nottingham, China. He is a member of the IEEE PELs AdCom and was an IEEE PELs Distinguished Lecturer from 2013 to 2017. He has published 500 academic publications in leading international conferences and journals. 